Syntax Literate: Jurnal Ilmiah Indonesia p-ISSN: 2541-0849

e-ISSN: 2548-1398

Vol. 7, No. 1, Januari 2022

\title{
ANALISIS PERAN (BALAI BESAR WILAYAH SUNGAI) BBWS PEMALI JUANA DALAM PENGELOLAAN GULMA AIR
}

\section{Agus Ananto Widodo, Hartuti Purnaweni, Kismartini}

Fakultas Ilmu Sosial dan Ilmu Politik Universitas Diponegoro (UNDIP) Semarang, Indonesia

Email: agusanantowidodo15@gmail.com, hartutipurnaweni@gmail.com,

kis_martini@yahoo.co.id

\begin{abstract}
Abstrak
Sumber daya air di Indonesia sangat melimpah, namun masih perlu pebaikan dalam pengelolaanya sehingga dapat dimanfaatkan secara lebih optimal. Salah satu sumber daya air di Indonesia dengan jumlah besar adalah Danau. Konferensi Nasional Danau Indonesia I pada 13 - 15 Agustus 2009 telah menghasilkan Kesepakatan Bali 2009 antara 9 kementrian yang menetapkan 15 danau kritis yang perlu diprioritaskan agar segera ditangani serius oleh pemerintah untuk mengambalikan fungsinya. Salah satu danau kritis tersebut adalah Danau Rawapening yang berada di Kabupaten Semarang. Permasalahan paling serius yang dihadapi adalah tertutupnya permukaan Danau Rawapening oleh gulma air. Penelitian ini bertujuan untuk mendiskripsikan bagaimana peran BBWS Pemali Juana sebagai aktor utama dalam pengelolaan gulma air di Danau Rawapening. Penelitian ini menggunakan metode deskriptif kualitatif dengan pengumpulan data melalui wawancara, observasi, dan dokumentasi. BBWS Pemali Juana melaksanakan kegiatan pengelolaan gulma air di Danau Rawapening dengan cara pengentasan gulma ke daratan sejak tahun 2017 dengan cara teknis atau menggunakan alat dalam prosesnya. Dalam proses pengentasan gulma tersebut masih terdapat beberapa kendala, diantaranya adalah keterbatasan tempat disposal akhir, belum optimalnya bantuan dari aktor lain, konflik dengan beberapa pihak, serta pengaruh cuaca dalam pelaksanaannya. Perlu adanya kerjasama dengan aktor lain dari pemerintah, swasta dan masyarakat agar pengelolaan Danau Rawapening lebih optimal dan efektif untuk mengembalikan fungsinya.
\end{abstract}

Kata Kunci: peran; BBWS pemali juana; pengelolaan gulma air; danau rawapening

\section{Abstract}

Water resources in Indonesia are very abundant, but still need improvements in their management so that they can be utilized more optimally. One of the water resources in Indonesia with a large amount is the Lake. The National Conference of Lake Indonesia I on 13 - 15 August 2009 has resulted in the Bali Agreement 2009 between 9 ministries that stipulate 15 critical lakes that need to be prioritized to be taken seriously by the government to enhance their functions. One of the critical lakes is Rawapening Lake which is located in Semarang Regency. The most serious problem faced is the closure of the surface of Rawapening Lake by water

$\begin{array}{ll}\text { How to cite: } & \text { Widodo. A.A., Hartuti Purnaweni \& Kismartini (2022) Analisis Peran (Balai Besar Wilayah Sungai) BBWS } \\ & \text { Pemali Juana dalam Pengelolaan Gulma Air. Syntax Literate: Jurnal Ilmiah Indonesia, 7(1). } \\ & \text { http://dx.doi.org/10.36418/ Syntax-Literate.v7i1.6016 } \\ \text { E-ISSN: } & \text { 2548-1398 } \\ \text { Published by: } & \text { Ridwan Institute }\end{array}$


weeds. This research aims to describe how the role of BBWS Pemali Juana as a major actor in the management of water weeds in Rawapening Lake. The study uses qualitative descriptive methods with data collection through interviews, observations, and documentation. BBWS Pemali Juana carries out water weed management activities in Rawapening Lake by alleviating weeds to the mainland since 2017 by technical means or using tools in the process. In the process of weed alleviation there are still some obstacles, including the limitations of the final disposal place, not optimal assistance from other actors, conflicts with several parties, and the influence of weather in its implementation. There needs to be cooperation with other actors from the government, private sector and the community so that the management of Rawapening Lake is more optimal and effective to restore its function.

Keywords: role; BBWS pemali juana; management of water weeds; swamp lake

Received: 2021-12-20; Accepted: 2022-01-05; Published: 2022-01-15

\section{Pendahuluan}

Sumber daya yang ada saat ini semakin terbatas. Eksplorasi, pemanfaatan dan pengelolaan sumber daya yang ada saat ini menjadi penting dan harus menjadi prioritas perhatian Negara (Simarmata et al., 2021). Sementara itu, pemanfaatan dan pengelolaan sumber daya di Indonesia saat ini masih belum optimal kaitannya dengan peningkatan pendapatan nasional dan peningkatan kesejahteraan rakyat. Sumber daya air merupakan salah satu sumber daya yang melimpah di Indonesia dan harus dikelola secara serius. Potensi sumber daya air di Indonesia yang belum dimanfaatkan secara optimal salah satunya adalah danau. Jumlah danau di Indonesia yang sangat banyak membuat pengelolaannya masih belum optimal, bahkan terdapat beberapa danau di Indonesia yang kondisinya kritis.

Penetapan danau kritis di Indonesia didasari oleh Konferensi Nasional Danau Indonesia I pada 13 - 15 Agustus 2009 yang telah menghasilkan Kesepakatan Bali 2009 antara 9 menteri tentang pengelolaan danau berkelanjutan dalam mengantisipasi perubahan iklim global. Pada konferensi ini telah ditetapkan lima belas danau yaitu Danau Toba, Maninjau, Singkarak, Kerinci, Tondano, Limboto, Poso, Tempe, Matano, Mahakam, Sentarum, Sentani, Batur, Rawa Danau, dan Rawapening yang masingmasing mempunyai karakteristik kerusakan masing-masing.

Salah satu danau yang ditetapkan adalah Danau Rawapening di Kabupaten Semarang. Danau Rawapening merupakan danau semi alami yang letaknya diantara tiga kota besar yaitu Yogyakarta, Solo dan Semarang. Danau ini menjadi landmark Provinsi Jawa Tengah (Bappeda Propinsi Jawa Tengah, 2005). Namun kondisi Danau Rawapening saat ini menjadi kritis, padahal Danau Rawapening memiliki manfaat tinggi diantaranya sebagai sumber air tawar, produksi pangan, dan pengendali banjir. Terdapat perkiraan bahwa pada tahun 2021 Danau Rawapening akan menjadi daratan apabila tidak ditangani secara serius. 
Pada dasarnya akar permasalahan Danau Rawapening dapat dikelompokkan menjadi 3 kategori, yaitu permasalahan pada badan air (inti danau), permasalahan di daerah tangkapan air (DTA), dan permasalahan kelembagaan (Harlina, 2020).

Permasalahan badan air Danau Rawapening yang menjadi masalah utama adalah tidak terkontrolnya pertumbuhan gulma air yang menyebabkan berbagai macam masalah diantaranya menurunnya kualitas air, sedimentasi, berkurangnya jumlah cahaya yang masuk ke dalam air, rusaknya ekosistem air dan masih banyak masalah lainnya (Piranti, 2021). Penutupan permukaan danau oleh tumbuhan air tersebut semakin besar persentasenya, bahkan pada musim kemarau dapat mencapai 70\% (Soeprobowati, Tandjung, Sutikno, \& Gell, 2010).

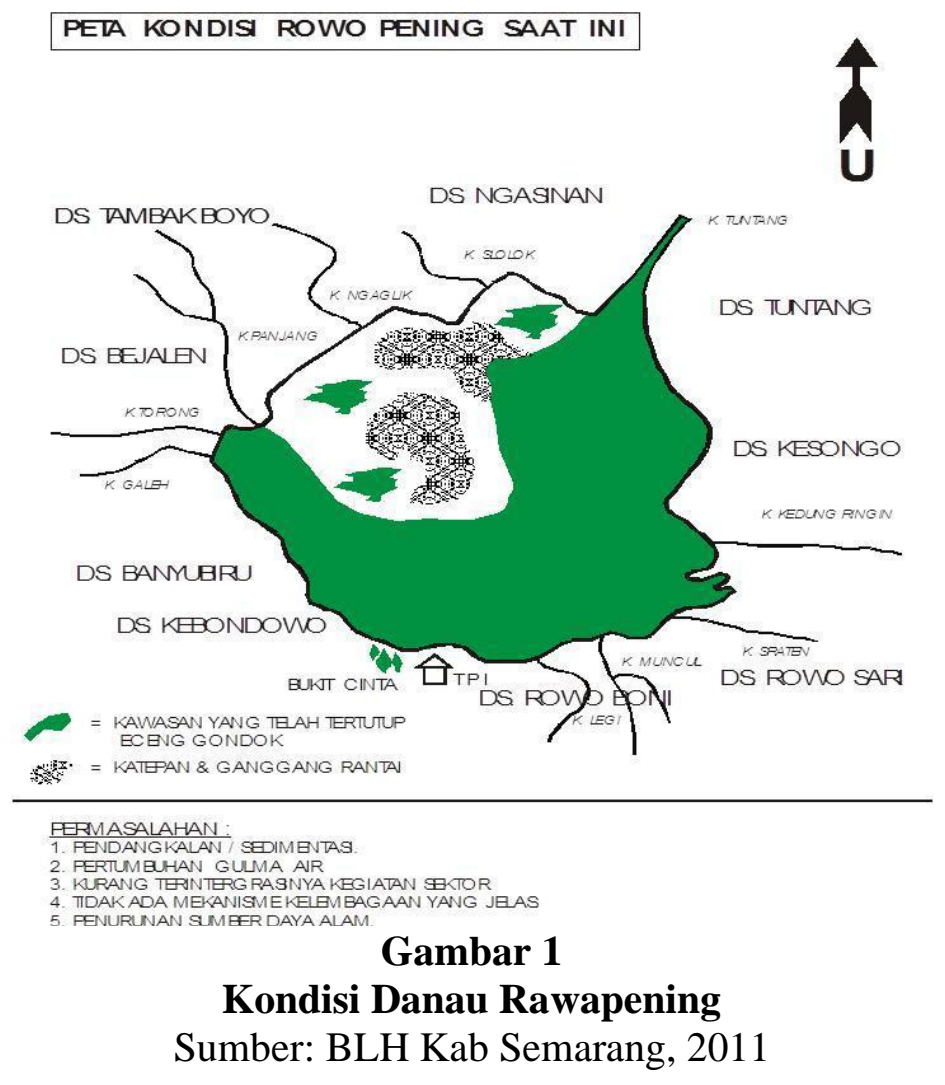

Sebuah pendekatan yang disusun oleh Kementrian Lingkungan Hidup yaitu Gerakan Penyelamatan Danau (GERMADAN) Rawapening terdiri dari aplikasi sains dan teknologi untuk remediasi badan danau dan DTA (Daerah Tangkapan Air) (Raharjo, Falah, \& Cahyono, 2019), pengembangan kelembagaan untuk peningkatan pengelolaan danau, dan pemberdayaan masyarakat dalam pengelolaan dan konservasi danau. ketiga pendekatan diatas saling terintegrasi dan dapat dirumuskan menjadi 6 program Super Prioritas (Pokok) dan 11 kegiatan Prioritas (Pendukung).

Program super prioritas pertama dalam pendekatan GERMADAN adalah pengelolaan gulma air yang didominasi oleh tumbuhan enceng gondok (Jamaldi, 2017). Tumbuhan ini berkembang sangat cepat di Danau Rawapening karena beberapa faktor pendukung pertumbuhannya. Pengelolaan gulma air di Danau Rawapening saat ini 
dilakukan oleh Balai Besar Wilayah Sungai Pemali Juana, dibawah Direktorat Jenderal Sumber Daya Air Kementrian Pekerjaan Umum dan Perumahan Rakyat. Perannya dalam pengelolaan danau dengan melakukan pengentasan gulma air yang menutupi permukaan danau sangat penting karena BBWS Pemali Juana menjadi aktor utama yang memegang peran penting untuk mengatasi masalah utama yang dihadapi Danau Rawapening. Berdasarkan latar belakang diatas maka dalam penelitian ini akan dideskripsikan bagaimana peran BBWS Pemali Juana dalam pengelolaan gulma air di Danau Rawapening.

Menurut Nicholas Henry dikutip dalam (Pasolong, 2017), administrasi publik adalah suatu kombinasi yang kompleks antara teori dan praktik, dengan tujuan mempromosikan pemahaman terhadap pemerintah dalam hubungannya dengan masyarakat yang diperintah, dan juga mendorong kebijakan publik agar lebih responsif terhadap kebutuhan sosial. Administrasi publik berusaha melembagakan praktik praktik manajemen agar sesuai dengan nilai efektivitas, efisiensi, dan pemenuhan kebutuhan masyarakat secara lebih baik.

Kebijakan Publik menurut Thomas Dye dikutip dalam (Solahuddin, 2010) adalah apapun pilihan pemerintah untuk melakukan atau tidak melakukan (public policys whatever goverments choose to do or not to do). Konsep tersebut sangat luas karena kebijakan publik mencakup sesuatu yang tidak dilakukan oleh pemerintah di samping yang dilakukan oleh pemerintah ketika pemerintah menghadapi suatu masalah publik. Definisi kebijakan menurut Thomas Dye tersebut mengandung makna bahwa (1) kebijakan publik tersebut dibuat oleh badan pemerintah, bukan organisasi swasta; (2) kebijakan publik menyangkut pilihan yang harus dilakukan atau tidak untuk dilakukan oleh badan pemerintah.

Di dalam studi proses kebijakan, aktor-aktor kebijakan berasal dari berbagai macam lembaga yang tercakup dalam supra struktur politik maupun infra struktur. Para ahli mengidentifikasikan aktor-aktor dengan berbagai macam sebutan. para aktor tersebut masing-masing mempunyai karakteristik yang menunjukkan kekuatannya mempengaruhi proses kebijakan (Solahuddin, 2010).

Gonsalves dalam (Hekmatyar, Kismartini, \& Santoso, 2015) mendeskripsikan aktor implementasi atas siapa yang memberi dampak dan/atau siapa yang terkena dampak kebijakan, program, dan aktivitas pembangunan. Mereka bisa laki-laki atau perempuan, komunitas, kelompok sosial ekonomi, atau lembaga dalam berbagai dimensi pada setiap tingkat golongan masyarakat. Pada umumnya peran aktor dalam implementasi dibagi menjadi 3 yaitu pemerintah, swasta, dan masyarakat. Setiap aktor tersebut memiliki peranan yang berbeda-beda sehingga perlu adanya pemetaan tentang kontribusi yang diharapkan dari masing-masing aktor.

Thompson dalam (Wibowo \& Rostyaningsih, 2016) mengungkapkan bahwa peran aktor dalam pelaksanaan suatu kebijakan atau program dipengaruhi oleh kekuatan (power) dan kepentingan (interest) yang dimiliki oleh aktor tersebut. Selain itu terdapat 4 unsur yang perlu diperhatikan dalam mengetahui faktor penentu keberhasilan peran aktor dalam implementasi suatu kebijakan (Yakin, Sulandari, \& Lituhayu, 2013) yaitu: 
1. Partisipasi aktor, yaitu dengan mengetahui bagaimana peran aktor-aktor terkait dalam pelaksanaan suatu kebijakan. Partisipasi bisa diartikan sebagai keterlibatan seseorang secara sadar ke dalam interaksi sosial dalam situasi tertentu.

2. Perspektif aktor, yaitu dengan mengetahui bagaimana aktor-aktor memahami kebijakan. Menurut Sumaatmadja dan Winardit dalam (Atmadja, 2014) perspektif merupakan merupakan cara pandang seseorang atau cara seseorang berperilaku terhadap suatu fenomena kejadian atau masalah.

3. Aksesibilitas aktor, yaitu dengan mengetahui bagaimana akses aktor-aktor dalam pelaksanaan kebijakan. Aksesibilitas juga dapat dikatakan sebagai derajat kemudahan dicapai oleh orang, terhadap suatu objek baik itu kebijakan atau pelayanan. Seberapa jauh kemudahan dalam mendapatkan informasi (transmisi) dari atas maupun bawah dalam kegiatan pengimplementasian sebuah kebijakan.

4. Penentuan tindakan, yaitu dengan mengetahui bagaimana peran aktor dalam menentukan tindakan. Atas dasar rasionalitas tindakan sosial, Max Weber membedakan dalam empat kategori, dimana semakin rasionalitas tindakan sosial itu semakin mudah dipahami.

\section{Metode Penelitian}

Penelitian ini merupakan penelitian deskriptif dengan pendekatan kualitatif dan berusaha untuk mendeskripsikan (Cresswell, 2017), membandingkan dan menganalisis bagaimana peran BBWS Pemali Juana dalam pengelolaan gulma air di Danau Rawapening (Sugiyono, 2017). Situs penelitian ini adalah Balai Besar Wilayah Sungai Pemali Juana sebagai pelaksana kegiatan. Instrumen dalam menelitian ini menggunakan daftar pertanyaan (interview guide) yang ditanyakan kepada narasumber serta dokumendokumen pendukung lainnya guna melengkapi dan membantu proses penelitian. Subjek penelitian yaitu informan yang dipilih dengan teknik Purposive atau yang dianggap dapat menjawab permasalahan penelitian ini. Sumber data menggunakan data berupa kata-kata dan tindakan serta sumber tertulis. Teknik pengumpulan pada penelitian ini melalui observasi wawancara mendalam, dokumentasi serta menggabungkan dengan teknik triangulasi. Analisis data yang digunakan dalam penelitian ini yaitu menggunakan reduksi, penyajian data dan penarikan kesimpulan dan verifikasi untuk mendapatkan kesimpulan penelitian yang kredibel.

\section{Hasil dan Pembahasan}

\section{A. Peran BBWS Pemali Juana}

1. Kekuatan (power)

Dasar kekuatan BBWS Pemali Juana dalam pengelolaan gulma air Danau Rawapening adalah berdasarkan dari kebijakan pemerintah mengenai pengelolaan 15 Danau prioritas yang kondisinya saat ini kritis (hasil Konfrensi Bali). BBWS Pemali Juana merupakan aktor utama dalam pelaksanaan kebijakan ini. Sebelumnya pengelolaan Danau Rawapening oleh BBWS Pemali Juana dilakukan oleh unit kerja 2 (OP 2) kemudian karena beban kerja berlebih 
dan agar penyelesaian masalah di Danau Rawapening lebih fokus dan cepat dalam penyelesaiannya maka pada tahun 2017 dibentuklah unit kerja 4 (OP 4) yang fokus mengelola Danau Rawapening untuk menangani gulma air.

2. Kepentingan (interest)

Kepentingan BBWS Pemali Juana dalam pengelolaan gulma air di Danau Rawapening adalah mengentaskan gulma air yang menutupi permukaan air hampir 70\% dari luasannya. BBWS Pemali Juana sebagai pelaksana tugas dibawah Dirjen SDA Kementrian PUPR memiliki tanggung jawab untuk dapat mengembalikan fungsi dari Danau Rawapening yang merupakan salah satu sumber daya air yang dimiliki oleh Indonesia.

\section{B. Faktor penentu keberhasilan peran BBWS Pemali Juana}

1. Partisipasi

Partisipasi adalah apa yang dilakukan oleh aktor, dalam hal ini BBWS Pemali Juana melakukan pengentasan gulma air dengan bantuan alat. Alat yang digunakan diantaranya adalah 8 unit harvester, 1 unit truxor, 2 unit dreger, 1 unit exavator long arm, 1 unit exavator short arm, 1 unit amphibious long arm, 3 unit dump truck, dan satu unit tug boat dan ponton. Berbagai cara dilakukan untuk dapat mengurangi jumlah gulma air yang menutupi permukaan diantaranya dengan melakukan pengentasan lalu membuang ke disposal akhir. Usaha lain yang dilakukan adalah dengan membuat ring lalu menumpuk gulma air di sekeliling ring tersebut sehingga bagian tengahnya terbebas dari gulma air, hal ini dilakukan karena untuk membawa ke daratan jaraknya terlalu jauh. Pada saat musim kemarau karena pengaruh cuaca sehingga debit air menurun kegiatan yang dilakukan adalah melakukan pengerukan dasar danau agar alat yang digunakan bisa mencapai kumpulan gulma yang ada di tengah Danau Rawapening.

2. Perspektif

Perspektif BBWS Pemali Juana dalam pengelolaan gulma air di Danau Rawa pening sangat baik, dimana BBWS Pemali Juana melakukan usaha pengentasan gulma air agar permukaan danau tidak tertutup sehingga fungsinya dapat menjadi lebih optimal. BBWS Pemali Juana dibawah Dirjen SDA Kementrian PUPR sangat memahami bagaimana tugas dan fungsinya untuk mengelola sumber daya air yang ada.

3. Aksesibilitas

Aksesbilitas BBWS Pemali Juana secara intern sudah berjalan dengan baik, dimana pelaksana tugas yang ada dilapangan dapat menyampaikan kendala kepada atasan sehingga akan dapat ditentukan bagaimana solusi untuk menyelesaikan masalah tersebut sehingga tujuan BBWS Pemali Juana dalam pengentasan gulma air di Danau Rawapening lebih maksimal. Namun aksesbilitas BBWS Pemali Juana dengan aktor lain diluar organisasi sedikit mengalami kendala. Beberapa kali dilakukan rapat koordinasi untuk menyelesaikan masalah bersama, namun sampai saat ini BBWS Pemali Juana 
masih sangat membutuhkan bantuan dari stakeholder lainnya sehingga kinerjanya dapat lebih optimal. Salah satu kendala serius yang dihadapi adalah mengenai disposal akhir atau tempat pembuangan akhir dari gulma enceng gondok yang terbatas.

4. Penentuan Tindakan

Dalam pengelolaan gulma air di Danau Rawapening BBWS Pemali Juana menentukan target serta rencana kerja yang disusun dengan baik lalu dilaksanakan semaksimal mungkin. Hal ini menunjukkan bahwa penentuan tindakan yang dilakukan oleh BBWS Pemali Juana sudah baik dan terukur dengan jelas, hanya saja saat pelaksanaanya menemui beberapa kendala sehingga masih perlu adanya evaluasi dan perbaikan.

\section{Kesimpulan}

Dalam artikel ini dapat disimpulkan bahwa peran BBWS Pemali Juana adalah sebagai aktor utama/aktor kunci, dimana BBWS Pemali Juana memiliki kekuatan dan kepentingan yang tinggi dalam pengelolaan gulma air di Danau Rawapening. Kegiatan yang dilakukan oleh BBWS Pemali Juana bertujuan untuk mengentaskan gulma air yang menutupi permukaan danau. Untuk mencapai tujuan tersebut BBWS Pemali Juana melakukan berbagai program yang dibantu dengan alat sehingga dapat mengurangi jumlah gulma air sehingga fungsi danau nantinya dapat lebih maksimal. Permasalahan yang terjadi diantaranya adalah belum adanya kerjasama yang jelas dengan stakeholder lain baik dari pemerintah, swasta, atau masyarakat. Permasalahan lainnya yaitu kendala disposal akhir, konflik dengan pihak lain, termasuk kondisi cuaca yang mempengaruhi kinerja BBWS Pemali Juana dalam melaksanakan tugasnya harus segera diatasi dengan kebijakan yang tepat serta dukungan stakeholder lain sangat dibutuhkan sehingga gulma air yang menjadi masalah utama yang dihadapi Danau Rawapening dapat segera diselesaikan dengan baik. 


\section{BIBLIOGRAFI}

Atmadja, Nengah Bawa. (2014). Geria Pusat Industri Banten Ngaben di Bali Perspektif Sosiologi Komodifikasi Agama. Jurnal Kawistara, 4(2). Google Scholar

Bappeda Propinsi Jawa Tengah. (2005). Penyusunan Action Plan pengembangan kawasan Rawapening. Laporan Akhir. CV. Galihloka Semarang. Google Scholar

Cresswell, J. W. (2017). Research Design: Pendekatan Kualitatif, Kuantitatif, dan Mixed (Edisi Ketiga). Yogyakarta: Pustaka Belajar. Google Scholar

Harlina, Harlina. (2020). Limnologi: Kajian Menyeluruh Mengenai Perairan Darat. Gunawana Lestari. Google Scholar

Hekmatyar, Ghana Abdila, Kismartini, Kismartini, \& Santoso, R. Slamet. (2015). Analisis Peran Aktor Dalam Implementasi Program Kelurahan Ramah Lingkungan Di Kecamatan Banyumanik. Journal of Public Policy and Management Review, 5(1), 122-135. Google Scholar

Jamaldi, Jamaldi. (2017). Revitalisasi Nilai-Nilai Agama Dan Kearifan Lokal Dalam Gerakan Penyelamatan Dan Kelestarian Sumber Daya Alam Salingka Danau Maninjau Sumatera Barat. Islam Realitas: Journal of Islamic and Social Studies, 3(2), 149-162. Google Scholar

Pasolong, Harbani. (2017). Teori Administrasi Publik. Bandung: Alfabeta. Google Scholar

Piranti, Agatha Sri. (2021). Pengendalian Eutrofikasi Danau Rawapening. Retrieved from https://www.researchgate.net/publication/349454387

Raharjo, S. Agung Sri, Falah, Faiqotul, \& Cahyono, S. Andy. (2019). Germadan Rawa Pening: Tindakan Bersama Dalam Pengelolaan Common Pool Resources (Germadan Rawa Pening: Collective action in managing common pool resources). Jurnal Penelitian Pengelolaan Daerah Aliran Sungai (Journal of Watershed Management Research), 3(1), 1-12. Google Scholar

Simarmata, Marulam M. T., Sudarmanto, Eko, Kato, Iskandar, Nainggolan, Lora Ekana, Purba, Elvitrianim, Sutrisno, Eko, Chaerul, Muhammad, Faried, Annisa Ilmi, Marzuki, Ismail, \& Siregar, Tiurlina. (2021). Ekonomi Sumber Daya Alam. Yayasan Kita Menulis. Google Scholar

Soeprobowati, T. R., Tandjung, S. D., Sutikno, S. Hadisusanto, \& Gell, P. (2010). Stratigrafi diatom danau rawa pening: kajian paleolimnologi sebagai landasan pengelolaan danau. Makalah Seminar Nasional Limnologi V. Pusat Penelitian Limnologi-LIPI. Bogor (in Indonesian). Google Scholar

Solahuddin, Kusumanegara. (2010). Model dan aktor dalam proses kebijakan publik. Gava Media, Yogyakarta. Google Scholar 
Agus Ananto Widodo, Hartuti Purnaweni, Kismartini

Sugiyono. (2017). Metode Penelitian Kuantitatif, Kualitatif, dan R\&D. Bandung: Alfabeta.

Wibowo, Rizky Fajar, \& Rostyaningsih, Dewi. (2016). Analisis Aktor Implementasi Dalam Kebijakan Rencana Tata Ruang Wilayah Kota Semarang (Studi Kasus Di Kecamatan Gunungpati). Journal of Public Policy and Management Review, 5(4), 17-32. Google Scholar

Yakin, Husnul, Sulandari, Susi, \& Lituhayu, Dyah. (2013). Analisis Peran Aktor Dalam Formulasi Kebijakan Program Nasional Pemberdayaan Masyarakat Mandiri Perkotaan Di Kelurahan Kemijen, Kota Semarang. Journal of Public Policy and Management Review, 2(2), 91-100. Google Scholar

\section{Copyright holder:}

Agus Ananto Widodo, Hartuti Purnaweni, Kismartini (2022)

First publication right:

Syntax Literate: Jurnal Ilmiah Indonesia

This article is licensed under: 